\title{
In Memoriam Professor Gholamreza Walizadeh: The Chief Editor of Iranian Journal of Pediatrics and the Pioneer of Medical Writing in Iranian Pediatrics
}

\author{
Behdad Gharib ${ }^{1, *}$ and Ali Rabbani (iD ${ }^{1}$ \\ ${ }^{1}$ Children's Medical Center, Tehran University of Medical Sciences, Tehran, Iran \\ "Corresponding author: Children's Medical Center, Tehran University of Medical Sciences, Tehran, Iran. Email: behdad_gharib@yahoo.co.uk \\ Received 2021 December 14; Accepted 2022 January 06.
}

Keywords: History of Medicine, History of Pediatrics, Iran

Professor Gholamreza Walizadeh, a professor of pediatrics at Tehran University of Medical Sciences, Tehran, Iran, one of the founders of Iranian Journal of Pediatrics, and a pioneer in modern medical journalism in Iran, passed away in April 2021. He was born in 1932 in Tabriz, Iran, the center of eastern Azerbaijan Province.

His father knew English which was not a common trend in Iranian society at that time, and he was encouraged by his father to learn foreign languages. He began learning English at British Council when he was only 11 years old. He had a strong emotional connection and a good relationship with his mother and father, and they played an important role in encouraging him to study and educate. He learned reading and writing before entering primary school. After entering high school, he wrote and translated stories for children; however, his father was strongly opposed to this; maybe he thought that his son might be distracted from education or was worried that his son would join political parties.

In 1953, he went to Germany and started studying medicine at Hamburg University and continued to study pediatrics there. After completing complementary courses in France and the United States, he returned to Iran in 1970 and started working at the teaching hospitals of Tehran Medical School and tried to improve the quality of teaching and training of medical students. He was mainly engaged in neonatology and had been the chief editor of Iranian Journal of Pediatrics since its foundation 37 years ago up to the 30th volume, which is the first specialized pediatric journal in Iran. The journal was initially published in Persian (up to Vol 16, 2006) and has been published internationally in English since 2007.

He firmly believed that the community was suffering from illiteracy and ignorance. He saw that some individuals resisted vaccination, which bothered him a lot. Therefore, he became interested in children's education and building schools. In 2020, he donated all his salary for decades of university work and retirement to charities for building schools. His colleagues and students will always remember him as someone who devoted his life to the education of the youth and the new generation.

\section{Footnotes}

Authors' Contribution: Behdad Gharib: Collecting the information and writing the manuscript; Ali Rabbani: Collecting the information and writing the manuscript.

Conflict of Interests: The authors declare that there is no conflict of interest. 


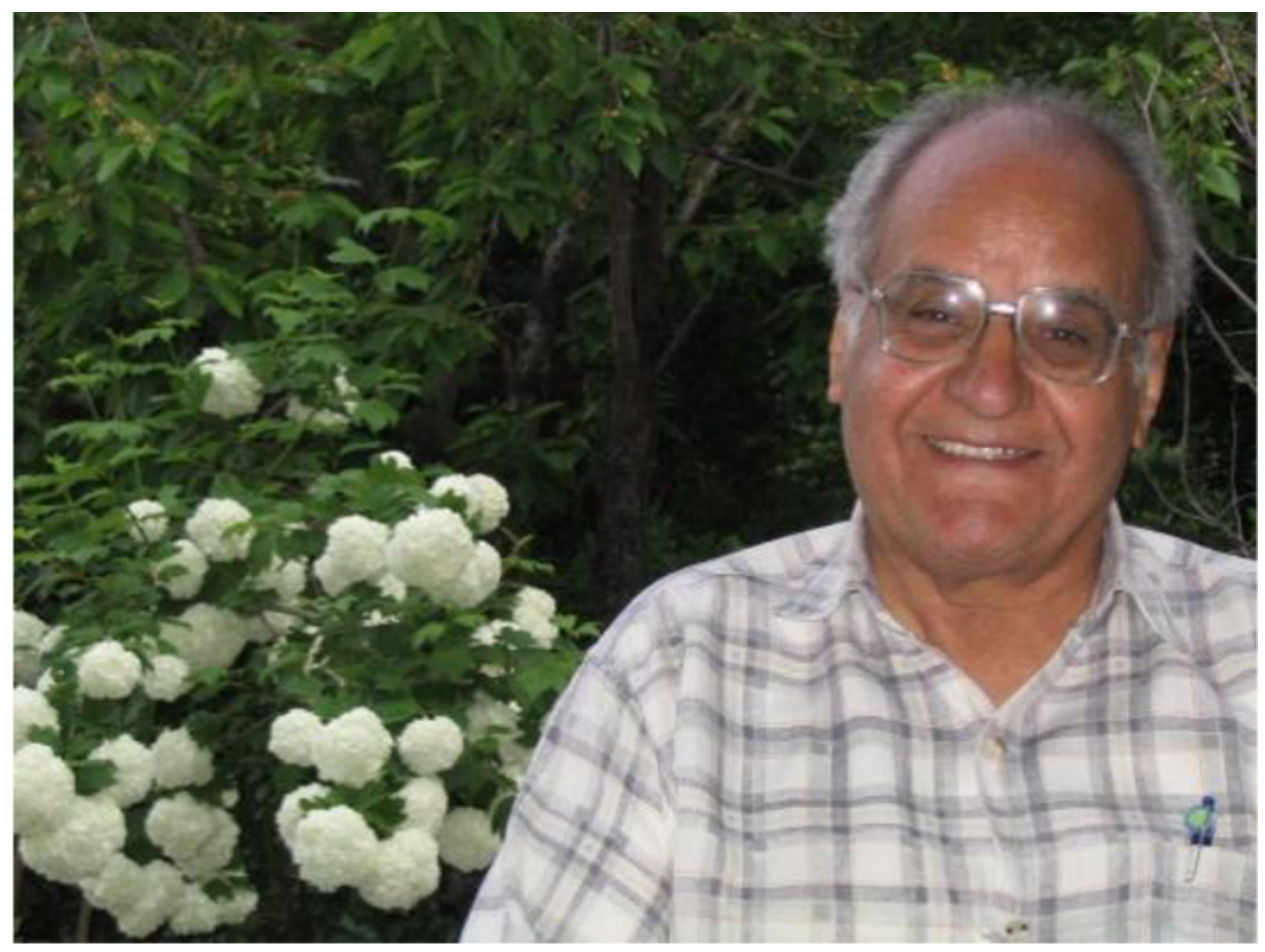

Figure 1. Professor Gholamreza Walizadeh 